\title{
Capture and storage of plant genomic DNA on a readily available cellulose matrix
}

\author{
Megan M Thompson ${ }^{1}$ \& Estelle M Hrabak $k^{*, 1}$ \\ ${ }^{1}$ Department of Molecular, Cellular \& Biomedical Sciences, University of New Hampshire, 46 College Road, \\ Durham, NH 03824, USA
}

BioTechniques 65: 285-287 (November 2018) 10.2144/btn-2018-0109

Keywords: DNA $\bullet \mathrm{FTA}^{\circledR}$ Cards $\bullet$ FTA purification reagent $\bullet$ PCR $\bullet$ polymerase chain reaction

\begin{abstract}
Whatman FTA ${ }^{\circledR}$ Cards are a fast and efficient method for capturing and storing nucleic acids but can be cost-prohibitive for large numbers of samples. We developed a method that substitutes a readily-available cellulose matrix and homemade washing buffer for commercial FTA Cards and FTA Purification Reagent. This method is suitable for long-term storage of DNA from many plant species prior to PCR.
\end{abstract}

In protocols where large numbers of DNA samples are collected, stored and later analyzed by PCR, decreasing the time and/or cost associated with preparing the DNA templates is desirable. For Arabidopsis thaliana leaf samples, the method of Klimyuk et al. [1] is quick and low cost, samples become less reliable as PCR templates after several weeks of storage at $4^{\circ} \mathrm{C}$ or $-20^{\circ} \mathrm{C}$. As an alternative, Whatman FTA ${ }^{\oplus}$ Cards (GE Healthcare Life Sciences, PA, USA), which are impregnated with proprietary chemicals, can be used to collect and store DNA samples [2-5]. Samples (body fluids or plant tissue) are pipetted or imprinted onto FTA ${ }^{\circledR}$ Cards, then dried completely for storage. When DNA is needed for PCR, small disks are removed from the card, washed twice with commercial FTA ${ }^{\circledast}$ Purification Reagent and then twice with $\mathrm{TE}_{0.1}$ (10-mM Tris-Cl, pH 8.0, 0.1-mM EDTA). Disks are dried completely at room temperature for at least $1 \mathrm{~h}$ before adding PCR reagents. While this method is relatively fast and efficient, the FTA ${ }^{\circledR}$ Purification Reagent and FTA $^{\oplus}$ Cards are costly. We investigated reliable and cost-effective substitutions for these materials.

As a replacement for commercial FTA ${ }^{\circledR}$ Purification Reagent to wash $\mathrm{FTA}^{\oplus}$ paper disks, we tested five other solutions: homemade TENT buffer (10-mM Tris-Cl, $\mathrm{pH}$ 8.0, 1-mM EDTA, 12-mM NaCl, and 2.5\% Triton X-100), sterilized deionized water, $\mathrm{TE}_{0.1}, 20-\mathrm{mM} \mathrm{NaOH}$, or $1 \% \mathrm{SDS}$. Both $20-\mathrm{mM} \mathrm{NaOH}$ and $1 \%$ SDS have been previously reported as alternative washing solutions for $\mathrm{FTA}^{\circledR}$ paper disks [6]. Testing was performed using leaves from 4-week-old $A$. thaliana ecotype Columbia-0 and the amplicon was a region from an Arabidopsis protein phosphatase gene. FTA ${ }^{\circledR}$ paper disks washed with water, $\mathrm{TE}_{0.1}, \mathrm{NaOH}$, or SDS yielded inconsistent results (data not shown). Products were consistently generated from disks washed with either TENT buffer or commercial FTA ${ }^{\circledR}$ Purification Reagent (data not shown); thus, homemade TENT buffer was used for the initial two washes in all subsequent experiments.

Next, we investigated alternatives to FTA $^{\circledast}$ Cards for sample storage and to $\mathrm{TE}_{0.1}$ for the final wash solution. Since DNA tightly associates with cellulose fibers [7], we tested three cellulose-based matrices: untreated Grade 1 filter paper (Whatman) and either untreated or treated grade 238 chromatography paper (VWR International, Radnor, PA, USA). Treated paper was prepared by soaking in Paper Washing Buffer (400 mM Tris-Cl [pH 8.0], $5 \%$ sodium dodecyl sulfate [SDS], 25-mM EDTA) for $2 \mathrm{~h}$, followed by air-drying at room temperature overnight. Treated paper can be stored at room temperature for at least 6 months prior to use. The treated paper was sandwiched between pieces of parchment paper to prevent contamination of tools while performing tissue printing and to avoid physical contact between samples during storage. Plant leaf tissue was pressed into the paper by rubbing the overlaid parchment paper using moderate pressure from a ceramic pestle. The cellulose matrix was dried for at least $1 \mathrm{~h}$ before extracting $1.5-\mathrm{mm}$ disks using a Miltex biopsy punch (Ted Pella, Inc., Redding, CA, USA). We tested three alternatives to $\mathrm{TE}_{0.1}$ for the final two washes: $100 \%$ isopropanol, $100 \%$ ethanol, or sterilized, deionized water. After the final washes, samples were dried for $20 \mathrm{~min}$ in a vacuum centrifuge (Vacufuge Concentrator 5301, Eppendorf, Hauppauge, NY, USA) at $45^{\circ} \mathrm{C}$. PCR Master Mix 1 (see Supplementary Protocol) was added directly to the disks immediately prior to thermal cycling. To streamline the procedure, multiple disks from the same DNA sample can be washed together using $100 \mu \mathrm{l}$ of each wash solution per disk. PCR products from treated chromatography paper were indistinguishable from products from FTA ${ }^{\oplus}$ Cards (Figure $1 \mathrm{~A} \& \mathrm{~B})$. This experiment also indicated that the initial washes were essential for robust amplification, while the final washes were not as important. Untreated chromatography paper was not suitable for DNA storage (Figure 1C). Untreated filter paper tended to warp when plant material was applied, which made subsequent manip-

\section{METHOD SUMMARY}

Here we report a low-cost method for capture and long-term storage of plant genomic DNA on chromatography paper. Stored DNA can be prepared for use as a PCR template in less than $1 \mathrm{~h}$. 


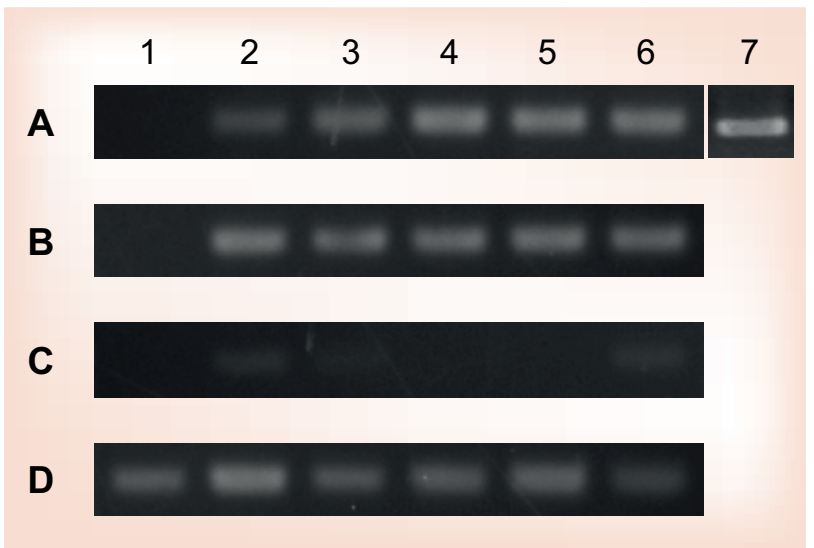

Figure 1. Comparison of four cellulose matrices and five washing conditions for isolation of DNA for PCR. Arabidopsis thaliana ecotype Columbia-0 leaf tissue was imprinted onto (A) commercial FTA ${ }^{\circledR}$ Card, (B) treated grade 238 chromatography paper, (C) untreated grade 238 chromatography paper, or (D) untreated grade 1 filter paper. Initial wash treatments were: (1) unwashed; (2-6) washed twice with TENT buffer; (7) washed with commercial FTA ${ }^{\circledast}$ Purification Reagent. Final wash treatments were: (1-2) no wash (3) $100 \%$ isopropanol, (4) $100 \%$ ethanol, (5) water or (6-7) TE $\mathrm{T}_{0.1}$. PCR products (491 bp) were visualized on a $1.5 \%$ agarose gel using ethidium bromide.

ulations difficult (Figure 1D); as a result, this matrix was eliminated from further consideration.

To test whether Arabidopsis DNA was stable for 1 month before amplification, PCR was performed 1 day, 1 week or 4 weeks after application of leaf tissue to commercial $\mathrm{FTA}^{\oplus}$ Cards or treated chromatography paper. Disks were washed twice with TENT buffer and twice with $\mathrm{TE}_{0,1}$ before thermocycling. Samples

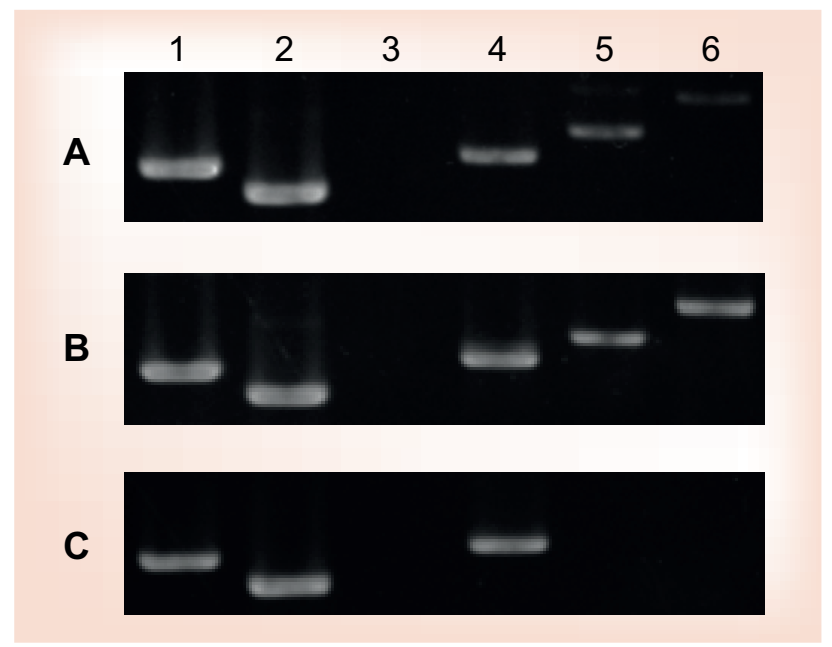

Figure 2. Comparison of cellulose matrices for amplification of GAPDH genes from a variety of plants. Cellulose matrices tested were: (A) FTA ${ }^{\circledast}$ Card, (B) treated grade 238 chromatography paper, or (C) untreated grade 238 chromatography paper. Young leaves imprinted on each celIulose matrix were from: (1) Cucumis sativus cv. Diva (cucumber), (2) Solanum lycopersicum cv. Ceylon (tomato), (3) Lactuca sativa cv. Outredgeous (lettuce), (4) Cucurbita pepo cv. Super Pik (summer squash), (5) Allium fistulosum x A. cepa cv. Guardsman (onion), (6) Beta vulgaris subsp. vulgaris cv. Bright Lights (Swiss chard). All disks were washed twice with TENT buffer and twice with $T E_{0.1}$. PCR products were separated on a $1.5 \%$ agarose gel and detected with ethidium bromide. on FTA $^{\circledR}$ Cards and treated chromatography paper both amplified well after 4 weeks of storage at room temperature (data not shown).

Next, we investigated the performance of DNA from other plant species when young leaves of field-grown plants were imprinted on FTA ${ }^{\circledR}$ Cards versus treated or untreated chromatography paper. Two sequential reactions were used to amplify glyceraldehyde3-phosphate dehydrogenase (GAPDH) gene fragments of unknown sequence; the first reaction contained a degenerate primer pair, followed by a second reaction with a nested primer from all matrices imprinted with Crocus sativus, Solanum lycopersicum, and Cucurbita pepo (Figure 2). Lactuca sativa DNA was not amplified when imprinted on any of the matrices but did yield product if purified genomic DNA was used as template with the GAPDH primers (data not shown). B. vulgaris DNA was amplified only from the treated chromatography paper and not from FTA ${ }^{\circledast}$ Cards, while both matrices worked for Allium DNA. These results indicate that some plant species may contain compounds that interfere with storage or amplification on certain matrices.

Our results show that: i) grade 238 chromatography paper pretreated with homemade Paper Washing Buffer is a reasonable substitute for Whatman $\mathrm{FTA}^{\circledR}$ Cards for many plant species; ii) homemade TENT buffer is a reliable replacement for $\mathrm{FTA}^{\circledR}$ Purification Reagent; and iii) the final disk washes can be performed with a variety of reagents. Sample processing time can be reduced by processing multiple disks from the same sample together and by using a vacuum centrifuge to dry the disks after the final wash. A detailed protocol is available online.

\section{Acknowledgments}

We thank the GEN 606 Genetics Laboratory class at the University of New Hampshire for performing the initial amplifications of the GAPDH gene from purified genomic DNA.

\section{Competing \& financial interests disclosure}

The authors have no relevant affiliations or financial involvement with any organization or entity with a financial interest in or financial conflict with the subject matter or materials discussed in the manuscript. This includes employment, consultancies, honoraria, stock ownership or options, expert testimony, grants or patents received or pending, or royalties.

No writing assistance was utilized in the production of this manuscript.

\section{Open access}

This work is licensed under the Attribution-NonCommercial-NoDerivatives 4.0 Unported License. To view a copy of this license, visit http://creativecommons.org/ licenses/by-nc-nd/4.0/

\section{Supplementary data}

To view the supplementary data that accompany this paper please visit the journal website at www.future-science.com/ doi/full/10.2144/btn-2018-0109

\section{References}

Papers of special note have been highlighted as: - of interest

1. Klimyuk VI, Carroll BJ, Thomas CM, Jones JDG. Alkali treatment for rapid preparation of plant material for reliable PCR analysis. Plant J. 3(3), 493-494 (1993). 
- A classic method for rapid isolation of plant DNA.

2. Beck IA, Drennan KD, Melvin AJ et al. Simple, sensitive, and specific detection of human immunodeficiency virus type 1 subtype B DNA in dried blood samples for diagnosis in infants in the field. J. Clin. Microbiol. 39(1), 29-33 (2001).

3. Lin JJ, Fleming R, Kuo J, Matthews BF, Saunders JA. Detection of plant genes using a rapid, nonorganic DNA purification method. Biotechniques 28(2), 346-350 (2000). - $\quad$ One of the first examples of gene amplification from both monocots and dicots using DNA collected on FTA ${ }^{\circledR}$ Cards.
4. Adugna A, Sweeney PM, Snow AA. Optimization of a high throughput, cost effective, and all-stage DNA extraction protocol for sorghum (Sorghum bicolor). J. Agr. Sci. Technol. 5(2), 243-250 (2011). - Demonstration that DNA can be collected on either FTA ${ }^{\circledR}$ Cards or Whatman chromatography paper under field conditions using simple tools.

5. Wolfgramm Ede V, De Carvalho FM, Aguiar VR et al. Simplified buccal DNA extraction with FTA Elute Cards. Forensic. Sci. Int. Genet. 3(2), 125127 (2009).

6. Zhou H, Hickford JG, Fang Q. A two-step procedure for extracting genomic DNA from dried blood spots on filter paper for polymerase chain reaction amplification. Anal. Biochem. 354(1), 159-161 (2006).
7. Alberts B, Herrick G. [11] DNA-cellulose chromatography. Methods Enzymol. 21, 198-217 (1971).

First draft submitted: 7 October 2017;

Accepted for publication: 10 July 2018

Address correspondence to: Estelle M Hrabak, Department of Molecular, Cellular \& Biomedical Sciences, University of New Hampshire, 46 College Road, Durham, NH 03824, USA; estelle.hrabak@unh. edu

To purchase reprints of this article contact: s.cavana@future-science.com

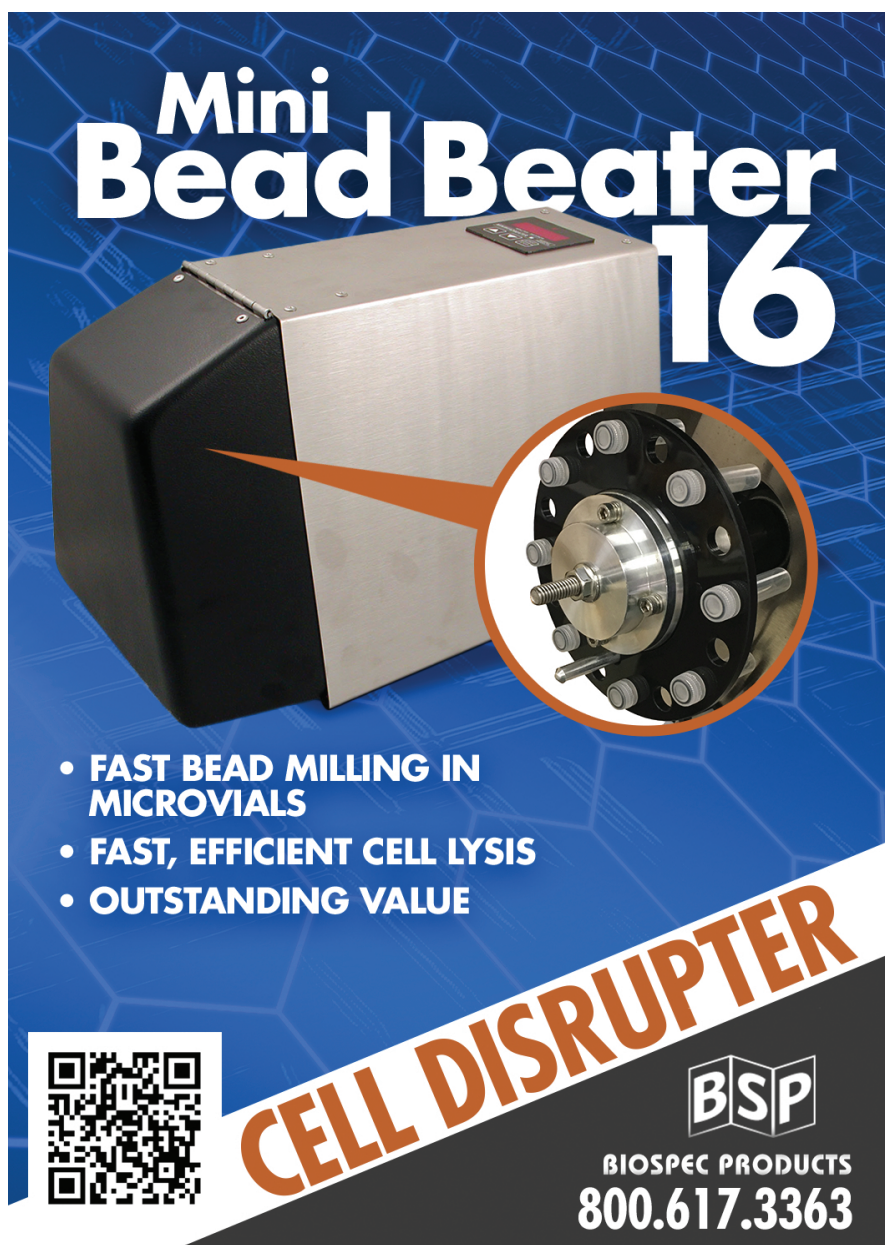

